\title{
When Porter's generic strategies are not enough: Complementary strategies for turnaround situations
}

\author{
Marius Pretorius ${ }^{1}$
}

Porter's generic strategy matrix, which highlights cost leadership, differentiation and focus as the three basic choices for firms, has dominated corporate competitive strategy for the last thirty years. According to this model, a venture can choose how it wants to compete, based on the match between its type of competitive advantage and the market target pursued, as the key determinants of choice (Akan, Allen, Helms \& Spralls, 2006:43).

Porter's model functions on the assumption that the venture is operating "normally" (profiting from demand for its product) in a competitive environment. But what if the venture faces trouble such as a turnaround situation? Now it is not enough to choose from low cost, differentiation or focus as the strategy; the venture needs an additional guideline. Leaders must now interpret for themselves the complexities of the turnaround situation, as the generic strategies alone do not meet the need.

Researchers have not yet come up with a model for selecting strategies in turnaround situations to match Porter's model for generic competition. Turnaround situations are governed by a mix of preconditions that are often described in metaphors or as syndromes, because they are so complex, severe and urgent. The need for turnaround strategies is not new; most business ventures face trouble and decline somewhere in their life cycle. Starbucks, for example, is early in 2008 struggling with the most serious crisis in its history - much as McDonald's did at the beginning of the decade. In 2007 Starbucks' share price fell by 42\%, making it one of the worst performers on the NASDAQ exchange at the time (Economist, 2008:54).

I recently completed an extensive literature search of 200 research articles in an attempt to better understand the business failure phenomenon. A forthcoming article (Pretorius, 2008:In press) reports the results to the academic community, but the purpose of the current article is to share some of the findings with the manager and practitioner community, who are often faced with these complex situations and need practical guidelines on the ground.

The research tried to answer three questions:

What are the key determinants of a turnaround situation?

What complementary strategy will result in a turnaround of each turnaround situation?

What strategic practices support the different complementary strategies?

This led me to propose a conceptual matrix (like that of Porter) suggesting complementary strategies in response to each turnaround situation. The model was then presented to a focus group of practitioners (from a banking and risk background) for them to establish face validity and expand the list of practices for use with each strategy. The model was then briefly applied to the troubled situation of Starbucks, as at January 2008, to illustrate its value. Finally I developed cases for testing strategy practices for each turnaround situation in the field.

\footnotetext{
${ }^{1}$ Dr. Marius Pretorius, Associate Professor in strategy and turnaround, Department of Business Management, University of Pretoria, 0002, South Africa. He consults to ventures on strategy issues with a focus on those that experience distress and seek turnaround, and has published articles in the field of entrepreneurship. He has developed a practical turnaround simulator for education, in which participants can see the impact of their decisions and strategies immediately.
} 
The research process

The specific problem identified in this article is how to understand, make sense of, and devise complementary strategies for a venture in a turnaround situation. Primary data on turnarounds is thin on the ground (especially in developing countries), as failed firms simply disappear, while successes are attributed to "leadership ability" and consultants protect their strategies as intellectual property. Even when the failed attempts are spoken about, the explanations are likely to contain a number of biases (Shepherd, 2005:125).

My search involved all scientific resources from the ABI-Inform, Ebsco-host, Proquest, Blackwell and other databases for titles published since 1985. For major works, the date was not a limitation, especially when an article was referenced widely. Age of publication was also not considered important; relevance and contribution to the body of knowledge of failure were paramount.

After reading and analysing, I identified key concepts using grounded theory research (Corbin \& Straus, 1990:3). I categorised concepts into failure sub-domains (categories); turnaround-related issues formed part of one category.

Finally a framework to classify the turnaround situations was drawn up. I first presented the model to a panel of academics, asking them to identify its limitations and give alternative views, and then presented the model to a focus group of bank business managers (credit and risk division) whose jobs revolved mainly around declining ventures and practical turnarounds. Their experience in this field varied between 3 and 25 years. I asked the focus group members to agree on answers to four questions:

What are the key determinants of turnaround situation configurations?

What complementary strategy do you associate with each turnaround situation in the matrix? What strategic practices do you associate with the chosen strategy?

What value do you gain from the model?

I used their responses to validate the model and direct further research.

The model

Turnaround is defined for use in this study as follows: A venture has been turned around when it has recovered from a "decline that threatened its existence" to resume normal operations and achieve performance acceptable to its stakeholders (constituents), through reorientation of positioning, strategy, structure, control systems and power distribution. This turnaround definition implies that a declining firm can be rescued, while a firm that has failed cannot. Judicial actions are mostly associated with failed firms, less often with those in decline and very small ventures, which enter and exit informally. The turnaround situation, on the other hand, refers to a point in time when a turnaround event occurs and a turnaround manager or alternative leadership may be considered. Turnaround situations are determined by several factors that together create a set of unique preconditions. A turnaround situation is so complex that it is often described using metaphors (Bollen, Merthens, Meuwissen, Van Roak \& Shelleman, 2005) such as frogs (drowning frog, bullfrog and boiled frog), liabilities (Kale \& Arditi, 1998:458; Pretorius \& Holtzhauzen, 2008) (adolescence and obsolescence) or syndromes (Probst \& Raisch, 2005:90) (pre mature, ageing and burnout) to simplify its complexity and imprecision. 
Resource munificence (Castrogiovanni, 1991:542) refers to scarcity or abundance of critical resources that are needed when operating the venture. Firms mostly attempt turnarounds at advanced stages of decline, when they typically experience huge resource scarcity. Resource munificence is also referred to as organisation capital (Levinthal, 1991:397). Munificence, also known as "level of free assets" (Smith \& Graves, 2005:304), depends largely on previous decisions, organisational learning and history. It is a critical factor in the severity of the preconditions for the turnaround situation, and crucial in determining the success of interventions. Resource slack is probably the key determinant of both how severe the decline is and what turnaround options can be chosen in response. Unabsorbed resource slack (Barker \& Mone, 1998:1227) suggests increased ability to borrow funds and the ability to generate cash (liquidity) from the firm's assets, which gives it the ability and time to respond with recovery strategies.

Declining organisational capital is an important determinant of firm death. A firm cannot sidestep failure if it cannot meet the minimum threshold for organisation capital. The level of firm resources at the time of the turnaround attempt affects the declining firm's capacity to implement strategic change. Maintaining adequate resources while responding to decline is often a problem, because the decline process destroys the firm's resources (Barker \& Duhaime, 1997:13) over time. Moreover, resource munificence is not only financial in origin; management, human and capacity also forms part of the resource capital (Cressy, 2006:103). Resource munificence appears at the heart of the turnaround situation Pretorius, 2006).

Environmental munificence (capacity of the business environment to accommodate firms) as described by Francis \& Desai (2005:1205) determines the strategic options that ventures can choose from. Environmental munificence plays an important role in the preconditions and the ability of a firm to recover from decline. The matching of resource and environmental munificence thus governs the turnaround strategies.

Causality of the distress theory

The cause of decline and failure is frequently classed as either strategic or operational in nature Robbins \& Pearce, 1992:287). The literature suggests that it is easier for a business to respond to operational problems such as inefficiencies, cost relationship pressures, incorrect resource applications and managerial deficiencies, as in this case there is room to manoeuvre, and the contributing factors are more visible. In contrast, strategic causes have to do with weak or wrong positioning in the market, technological changes that govern demand determinants and loss of competitive advantage by the venture - all highly susceptible to external influences not clearly visible to the decision makers. Strategic factors have a close relationship with the external environment and the firm's response to changes in that environment. Strategic causes generally require more speedy action.

For a turnaround strategy to be effective in reversing decline, it has to address the declining firm's core problem. A broad generalisation is therefore that a turnaround situation is less severe if it is due to operational weaknesses, while it is more severe if it is strategically caused. The rationale is that operational preconditions can be corrected with relative ease and expectation of success, while strategic preconditions require directional change and the high-risk expectations typically associated with new venture creation. An unwise choice of new strategy by the turnaround manager will therefore have a more severe impact on potential recovery than will unwise operational decisions. 
Environmental munificence will also determine whether certain strategies are viable, as unforgiving environments, such as economic downturns, make it harder to achieve successful turnaround than beneficial environments, such as growing economies or operation in growth industries.

It therefore stands to reason that ineffective turnarounds often occur when management fails to correctly diagnose causes of the firm's decline and responds inappropriately (e.g. trying to increase efficiency when the firm's weak strategic position is the cause of the problem, or vice versa).

Answering two related questions can help the practitioner to know whether a cause requires strategic response or operational action:

Does the cause erode the competitive advantage of the firm? (Thus, does it erode demand for the firm's product/service?)

Is it necessary to seek repositioning of the product/service as a result?

If the answer is yes to both questions, the cause is highly likely to be strategic in nature. If the answer is no, this tends to indicate operational causes.

Resource munificence and origin of the "distress cause" are the two key determinants of the turnaround situation. When combined they form a matrix that is explored in the next section.

The Turnaround Matrix

Combining resource munificence and causality results in a matrix with four cells as shown in Figure 1. The four cells are described as: Performing well, Underperformance, Distress and Crisis, each representing a set of preconditions. We will explore each configuration individually.

Figure 1 Turnaround situations and their unique preconditions matrix

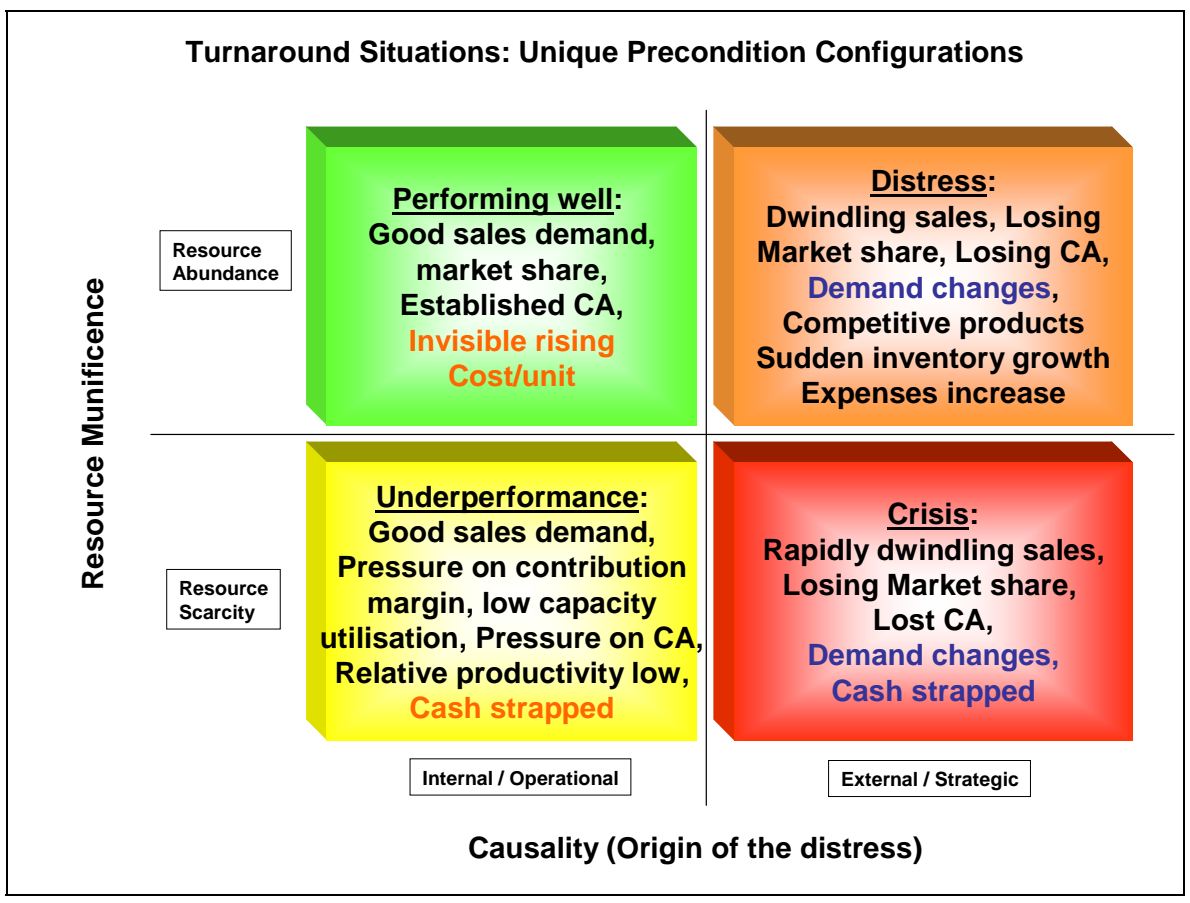

Source: Own compilation 
Performing well: Ventures in this cell are not experiencing a need for a turnaround. The venture has abundant resources and minimum causes of distress, and can operate normally, barring potential invisible inefficiencies. Typically it experiences good sales demand, growing market share and established competitive advantage. It will not be explored much further in this article.

Underperformance: This cell's preconditions are characterised by scarce resources (limited slack) and problems caused by weak internal operations. Despite good demand for its products, contribution margin is under pressure, capacity utilisation low, competitive advantage comes under pressure due to inability to respond to demand, productivity is low and the venture is cash strapped. Operations are weak and contain several types of inefficiencies such as rising inventory, low capacity utilisation and increasing debtor days. Increases in both demand and inventory are contradictory but point directly towards the very inefficiencies that create the underperformance.

Distress: This cell's preconditions are characterised by abundant resources but declining sales demand due to loss of competitive advantage. Market share is under pressure, probably due to growing demand for competitive or substitute products. Underlying a rise in inventory is the loss in demand for its own products. Because the venture has abundant resources, leadership is unenthusiastic about finding the real cause of the problem, namely loss in competitive advantage, and tends to blame it on "temporary misfortune". Management typically responds with increases in sales incentives, marketing and advertising budgets to overcome the problem, which they perceive as short-lived.

Crisis: If nothing is done about the distress situation or the wrong strategies (those that drain resources) are pursued, decline quickly turns into a crisis. This cell's preconditions are characterised by scarce resources and the pressure on cash becoming more pronounced due to the reduced sales. The venture is in the "intensive care unit". To increase sales, more credit is granted, which depletes cash levels even more. Reduced advertising (trying to reduce cost) weakens the competitive advantage further. Basically the venture direction is south.

Each of these turnaround situations is determined by its own configuration of preconditions, and many additional lesser variables may play a role or act as triggers. Each cell in the matrix would then need a complementary strategic thrust to solve the unique set of problems associated with the turnaround situation.

The generic strategies and their associated practices

Strategic practices are the actions that management undertakes to achieve its chosen strategy. Such practices, taken individually or in combination, should bring about the desired outcome of the strategy. Each turnaround situation demands a different strategy supported by specific practices. These practices are chosen based on their applicability to the specific market (environmental) conditions. Figure 2 shows the strategies for each turnaround situation with the key practices that drive such a strategy.

Given the preconditions associated with performing well, the venture is free to focus all its attention on a growth strategy. Growth can be achieved through organic and inorganic practices such as market development, pursuing new markets and acquisitions. Firms focus on strengthening their competitive advantages and build market share because they have abundant resources and are well positioned in the market.

Given the preconditions associated with underperformance, the venture must pursue an efficiency strategy to turn around successfully and move towards the 'performing well' quadrant. 
It must pursue efficiency by such practices as improving capacity utilisation, lowering inventory levels, improving collection processes, restructuring financing, better use of volume discount, improving supply chain activities and more. The focus is mainly on internal operations and doing the business right and better. These firms are well positioned but experience cash-flow problems due to their inefficiencies. Cost to income ratios typically deteriorates.

Given the preconditions associated with distress, the venture has little choice but to pursue a forced repositioning strategy. Because the repositioning is forced, the venture is under pressure to change direction quickly (finding an alternative value proposition), which means less time for extensive research about new products/services and market testing and therefore more chance of pursuing non-starters. The firm is on the back foot and focuses on "stop the bleeding" actions. Even worse than misjudging the right alternative products is if the leadership is blinded by the apparent resource abundance and tries to solve the problem by throwing resources into marketing and advertising efforts which have little or no effect. The bottom line is that competitive advantage is dwindling and so are cash reserves if "good money is thrown after bad opportunity". Lower-level management and sales staff have realised the problem and start to leave for more prosperous careers with competitors, aggravating the distress by depleting human capital. However, refocused positioning, differentiation to new products/services or diversification to alternative business/industry can be pursued, as there are still resources available.

Repositioning fundamentally asks for a new choice of Porter's generic strategic options as a focal point. In worst-case scenario it requires the start-up of new ventures, which involves determining the new positioning and where competitive advantage will be sought. So with abundant resources, Porter's matrix is still core, but when there is scarcity of resources, the focus moves towards finding efficiency first.

Figure 2 Strategies and practices to respond to the turnaround situations

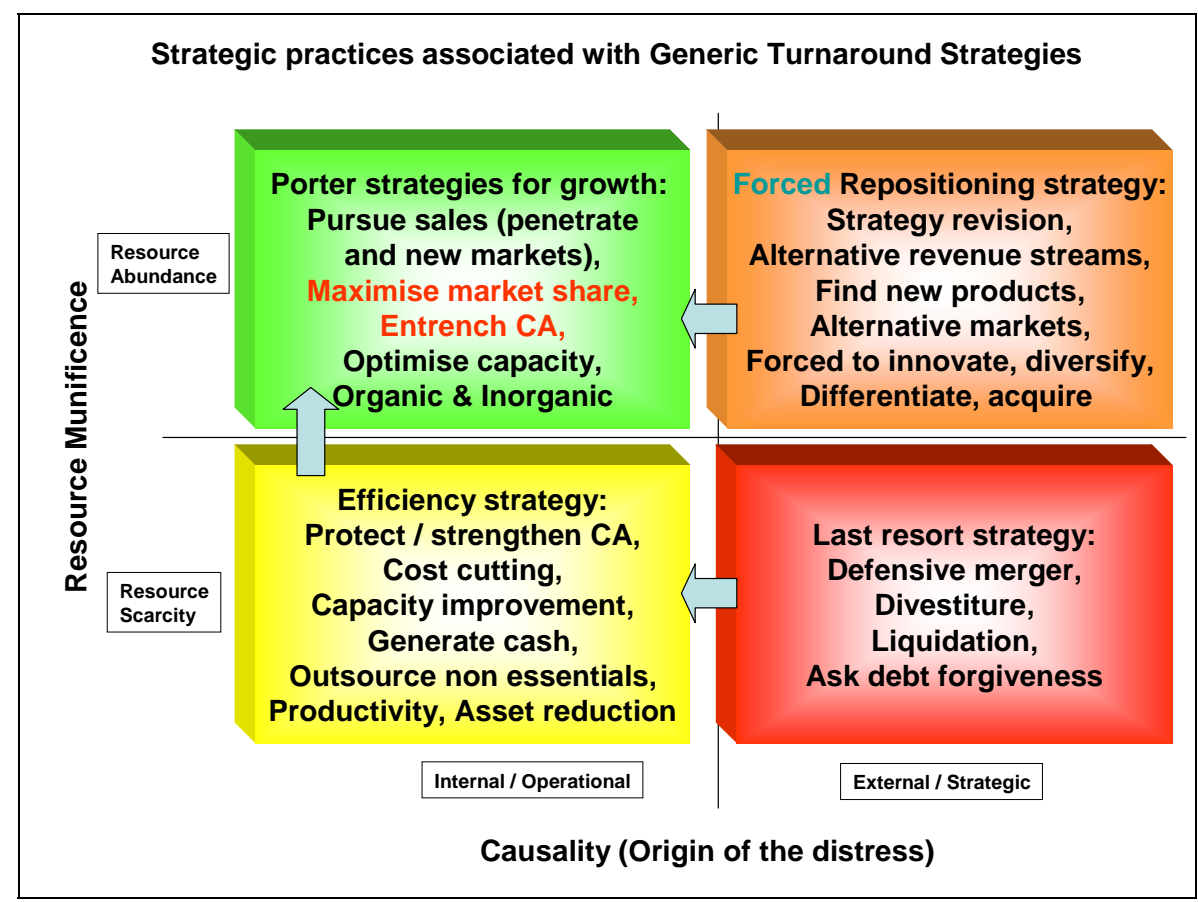

Source: Own compilation 
Lastly, given the preconditions associated with a crisis, the venture now has no choice but to pursue a last resort strategy. Cash is under severe strain and reduced advertising weakens the effectiveness of competitive advantage even further, while unfocused cost-cutting is the order of the day. There is little time for proper analysis and investigation; because of resource scarcity, poor decisions and poor acquisitions are made. This cell's preconditions are characterised by scarce resources, and the pressure on cash becomes more pronounced due to the tumbling sales. To achieve more sales, credit is often granted, which further depletes cash. Firms are sometimes forced to ask "debt-forgiveness" from creditors to stay in operation.

Sometimes it is possible (or necessary) to combine practices from different cells to find an optimal generic strategy. There is a place for combination strategy. The combined strategy is mostly applied to support forced reposition strategy or last-resort strategy. Successful efficiency strategies free up cash and drive down costs, which makes them easier to apply.

Discussion and application of the model

The focus group received the model with enthusiasm, which is encouraging as they had wide turnaround experience. Many felt that the model categorised the turnaround situations and associated strategies meaningfully. Compared with their previous haphazard use of the same practices, the model gives structure to the process of thinking about them as well as how to execute them. They felt that it would be useful in their communication with their clients.

The model suggests that the regression of a venture in decline is not necessarily a linear one through underperformance, decline, distress and then crisis. Figure 1 shows that the problems of underperformance differ from those of distress. The situation of the venture in distress is much more severe and urgent. I use the model as a screening tool when visiting a troubled venture for the first time - to great effect.

The focus group added several practices to the different generic turnaround strategies. Some of the key practices are shown in Figure 2.

One crucial finding of the group was that in current practice they pursue practices based mainly on financial performance and a "shotgun approach", while the proposed model suggests a more structured approach. Combination strategies are a prevalent feature of current practice.

Starbucks January 2008

Looking at the situation of Starbucks in January 2008, one could ask where it fits on the turnaround matrix. Without claiming to know the detailed ins and outs of the company, public knowledge from analyst reports and internal documents suggests that performance is down significantly, as measured by share price and announcements by management.

In late 2007, Howard Schultz stated: "Over the past ten years, in order to achieve growth, development and the scale necessary to go from less than 1000 stores to 13000 stores and beyond, I have had to make a series of decisions that, in retrospect, has led to the watering down of the Starbucks experience, and what some might call the commoditization of our brand".

Schultz sent an internal memo stating his view on their major problems. It includes:

Romance and theatre of coffee has disappeared.

Stores don't smell like coffee any more.

Stores have an uninspiring cookie-cutter design.

Reflect feeling of a chain store instead of warm feeling of 'neighborhood-store'. 
Use automated Espresso machines.

Answering the two questions posed earlier in this article to determine the cause of the distress, it is clear that there is intense pressure on Starbucks's current positioning and competitive advantage. At the same time Starbucks is known for its economies of scale, control over the coffee quality and cost control, suggesting high-level efficiencies. Schultz's reference to 'commoditisation', 'watering down' and automated espresso machines suggests that management focused on efficiency together with its recent all-out drive for growth. Confirmation of pressure on demand for its product comes from decreased transactions (1\%), despite increased number of stores in FY07Q4. The news that McDonalds plans to add Espresso machines to all their stores and that several independent stores are rising up means that substitutes are and will be freely available at a much lower price. The problem is therefore fundamentally strategic in nature and Starbucks is in the distress or crisis side of the matrix.

Starbucks is known for its staff morale and culture towards employees, suggesting high-level human capital. Expanding rapidly, its free cash is under pressure but it has "resource slack", which indicates the distress cell as the appropriate turnaround situation.

Being in distress, Starbucks therefore needs a "forced repositioning strategy". At the same time global economic squeeze is making consumers price sensitive. Starbucks had already replaced the CEO with Schultz, and from history and knowledge of Schultz and the business, one can only speculate on how he will pursue the repositioning. Rumour has it that Starbucks is testing some one-dollar coffee products as part of its innovation practices. The focused differentiation strategy it pursued in the past may now become a broad differentiation strategy to keep pace with the economic profile of its regular customers and potentially pursue lower-income segments (alternative markets). Schultz has already declared expansion of the international market a priority. Finding alternative revenue streams may prove more difficult, as Starbucks has pursued this vigorously in the past through expanding food products, music, ice-cream products and more, through joint ventures.

Moving from distress to performing well is much easier than to move from crisis directly to performing well, which is very unlikely. If a turnaround is attempted when in crisis, then the move should be towards the left of the matrix first (thus via efficiency) and then towards growth. Figure 2 also shows the directions that firms should aspire to when the process starts. Starbucks should take the direct route to move towards growth. It has already announced closure of some 100 "less profitable" stores. This practice is typically associated with efficiency strategy. Most turnarounds, in my experience, include several efficiency steps to free up funds to support other strategies.

Management implications

The expert opinions in the focus group (with well over 70 years' combined experience in turnarounds) furnish definite face validity to the model, and their support for its application bodes well for acceptance by practitioners in the field. They see it as a tool that will assist them to get the management on board earlier.

The benefits of the model, as a new perspective on the "messy" conditions associated with turnaround situations, include: 
Bank officials could use it to classify individual cases during their analysis process. Doing so would improve insight into the specific preconditions driving the turnaround situation. Managers could analyse their own venture to anticipate problems and prepare accordingly. Consultants and analysts could use the model to structure their analysis process before prescribing courses of action that might lead to better performance.

Academics could use it to eliminate "messy" descriptions and teach in a more structured way.

The strategies proposed in this study should not be seen as alternatives to those proposed by Porter, but rather as complementary to the model in view of the unique requirements of turnaround situations. The turnaround strategies should rather be seen as emergency moves that could put the venture back into normal operation so that it could compete with its chosen generic position of low cost leadership, differentiation or focus.

Study limitations and future research

Limitations of one study serve as challenges for future research. Firstly, the grounded theory approach that was used depends to some extent on the interpretation by the researcher and is therefore subject to our own biases and mental structures as determined by our own background and own turnaround experiences. While every attempt was made not to fall into these traps, I was still subject to this natural phenomenon.

Secondly, no empirical data is presented, though many of the articles used to support the concepts are backed by statistics. Privacy issues and the scarcity of primary data lessen this option to some extent, and I propose in-depth research of case studies to find support for the different concepts.

Thirdly, this study breaks new ground in research in this field. It therefore challenges other researchers to dispute the assumptions, or to find support for the strategies, or challenge them with primary data. Experimental research is under way using case samples that practitioners could evaluate to find practices associated with each turnaround strategy.

Finally, it opens the debate for policy on the appointment of the "turnaround supervisor". Is it possible that every turnaround situation as defined by the model would require a different level of supervisor involvement (Pretorius \& Holtzhauzen, 2008:In Press) and experience? For example, would it be necessary to involve judicial procedure if the turnaround situation suggests underperformance rather than crisis? This raises several new arguments about the required training and ability when appointing turnaround supervisors.

Acknowledgements

The contribution of the staff from the credit risk division of Nedbank is acknowledged with gratitude.

\section{References}

Akan, O., Allen, R.S., Helms, M.M. \& Spralls III, S.A. 2006. Critical tactics for implementing Porter's generic strategies. Journal of Business Strategy. 27(1) 43-53.

Barker, V.L III, \& Moné, M.A. 1998. The mechanistic structure shift and strategic reorientation in declining firms attempting turnarounds. Human Relations. 51(10) 1227-1258. 
Barker, V.L III, \& Duhaime, I.M. 1997. Strategic change in the turnaround process: Theory and empirical evidence. Strategic Management Journal. 18(1) 13-38.

Bollen, L.H.H., Mertens, G.M.H., Meuwissen, R.H.G., Van Roak, J.J.F \& Schelleman, C. 2005. Classification and analysis of major European business failures. Report by Maastricht Accounting, Auditing and Information Management Research Center (MARC), Maastricht. October. www.fdewb.unimaas.nl/aim/downloads/pdf/MARC\%20rapport\%20total.pdf Accessed 14 December 2005.

Castrogiovanni, G.J. 1991. Environmental munificence. Academy of Management Review. 16 (3) 542-565.

Corbin, J. \& Strauss, A. 1990. Grounded theory research: Procedures, canons and evaluative criteria. Qualitative Sociology. 13(1) 3-21.

Cressy, R. 2006. Why do most firms die young? Small Business Economics. 26 103-116.

Economist, 2008. Coffee wars: Starbucks ousts its boss and brings back its founder as a new threat emerges. January 12-18. 54-55.

Francis, J.D. \& Desai, A.B. 2005. Situational and organisational determinants of turnaround. Management Decision. 9 1203-1224.

Kale, S. \& Arditi, D. 1998. Business failures: Liabilities of newness, adolescence, and smallness. Journal of Construction Engineering and Management. November/December 458-464.

Levinthal, D.A. 1991. Random walks and organisation mortality. Administrative Science Quarterly. 36 397-420.

Pretorius, M. 2006. Building a theory for business failure. Paper presented at BCERC Conference Frontiers of Entrepreneurship Research, Bloomington. MA.

http://www.babson.edu/entrep/fer/papers06/.

Pretorius. M. 2008. Critical variables of business failure: A review and classification framework. South African Journal of Economic and Management Sciences. In Press.

Pretorius. M. \& Holtzhauzen, G.T.D. 2008. Critical variables of venture turnarounds: A liabilities approach. Southern African Business Review. In Press.

Probst, G. \& Raisch, S. 2005. Organizational crisis: The logic of failure. Academy of Management Executive. 19(1) 90-105.

Robbins, D.K \& Pearce II, J.A. 1992. Turnaround: Retrenchment and recovery. Strategic Management Journal. 13(4) 287-309.

Shepherd, D.A. 2005. The theoretical basis for my plenary speech about our successes and failures at research on business failure. Invited paper. Proceedings: Regional Frontiers of Entrepreneurial Research, Brisbane, February. 123-134.

Smith, M. \& Graves, C. 2005. Corporate turnaround and financial distress. Managerial Auditing Journal. 20(3) 304-320. 